\title{
Representative Lake Water Extent Mapping at Continental Scales Using Multi- temporal Landsat-8 imagery
}

\author{
Yongwei Sheng* ${ }^{1}$, Chunqiao Song ${ }^{1}$, Jida Wang ${ }^{2}$, Evan Lyons ${ }^{1}$, \\ Benjamin Knox ${ }^{1}$, Joshua Cox ${ }^{1}$, and Feng Gao ${ }^{3}$
}

${ }^{*}$ Correspondent author.

${ }^{1}$ Department of Geography

1255 Bunche Hall

University of California, Los Angeles (UCLA)

Los Angeles, CA 90095

Email: ysheng@geog.ucla.edu

Phone: 310-825-1415

${ }^{2}$ Department of Geography

118 Seaton Hall

Kansas State University

Manhattan, KS 66506

${ }^{3}$ Hydrology and Remote Sensing Laboratory

Agricultural Research Service

Beltsville, MD 20705-2350.

(C) 2015. This manuscript version is made available under the Elsevier user license http://www.elsevier.com/open-access/userlicense/1.0/ 


\section{Representative Lake Water Extent Mapping at Continental Scales Using Multi- temporal Landsat-8 imagery}

[Abstract] Inland lakes, important water resources, play a crucial role in the global water cycle and are sensitive to climate change and human activities. There clearly is a pressing need to understand temporal and spatial variations of lakes at global and continental scales. The recent operation of Landsat 8 extends the unprecedented Landsat record to over 40 years, allowing long-term, large-scale lake dynamics mapping at high resolutions. Using our circa-2000 lake product derived from Landsat 7 images as a reference, this research produces a circa-2015 map of representative lake extents and distributions, and addresses seasonal and inter-annual lake area variability using Landsat 8 images acquired in lake stable seasons at a continental scale. Oceania is chosen here as a case study as it contains a large group of salt lakes that exhibit high area variability and has the most intensive image coverage during the first 2.5-year operation of Landsat 8 . Accordingly, this paper describes an adaptive algorithm to automate lake mapping for various surface conditions using images acquired during lake stable seasons and a compositing scheme in the vector domain to generate a representative continental mosaic of lake extents from multi-temporal mapping. Our results demonstrate that these strategies and methods produce a highly reliable and representative composite of highlyvariable lake extents across Oceania, and are potentially applicable to other large-scale lake mapping projects using multi-temporal data.

Keywords: water body identification, adaptive mapping, salt lakes, seasonal variability, inter-annual variation 


\section{Introduction}

Inland lakes are critical components of global/regional hydrological and biogeochemical water cycles, as well as essential resources for life (Lehner and Döll 2004; Palmer et al. 2015). They are dynamic and complex aquatic ecosystems, which are sensitive to climate change and to human activities. The tremendous impacts of climate and human activity on lakes have been observed widely over the past several decades at regional and global scales (Shi et al. 2014; Smith et al. 2005; Song et al. 2013; Vorosmarty 2002; Wang et al. 2014). In addition, lakes serve as an integrative indicator of climate and environmental changes as well as human water use within their drainage basins. Changes in lake extent either reflect or have broad implications for regional water balance, ecosystems, biogeochemical cycles, exchange of energy and trace gases with the atmosphere, and human water consumption. Understanding the distribution and inundation variability of lakes is thus crucial for a wide range of socioeconomic, political, and scientific interests. Therefore, it is important to monitor lakes over time (Carpenter et al. 1992).

Lake observations are relatively simple to make on an individual basis but become difficult for a large number of lakes across broad areas and temporal scales (Benson and MacKenzie 1995; Khorram 1999; Pietroniro et al. 2005). Lakes across a large region are far too numerous to be surveyed by field-based methods, and satellite remote sensing offers the only feasible approach for systematic lake mapping and inventory at continental and global scales. Though coarse-resolution satellite sensors such as NOAA/AVHRR (National Oceanographic and Atmospheric Administration, Advanced Very High Resolution Radiometer, $\sim 1$ km resolution) (Bryant 1999) and 
Terra/Aqua MODIS (Moderate-resolution Imaging Spectroradiometer, 0.25 to $1 \mathrm{~km}$ resolutions) (McCullough et al. 2012) have been used in lake mapping at these scales, they are limited only to large lakes. Regional to global scale lake mapping represents a great challenge because lakes are abundant at small sizes and lake changes take place around shores at small amplitude, both requiring fine-resolution satellite imagery for adequate assessments. Dynamic lake mapping and change detection at continental and global scales was difficult in the past due to large data volumes and high costs of data purchase (Alsdorf et al. 2007), but neither remains as a significant constraint today.

The recent public release of the Landsat archive makes lake mapping and monitoring feasible and affordable even at a global scale. The U.S. Geological Survey (USGS) released Landsat products, the longest satellite image archive, to the public in 2008, providing the possibility to monitor lake dynamics at 30 meter resolution at global and continental scales. With Landsat 8, currently in operation since its launch in February 2013, carrying the OLI (Operational Land Imager, $30 \mathrm{~m}$ resolution) sensor, the Landsat mission is expected to continue into the next decade. Effective imaging technology, data processing, and sharing procedures provide more opportunities of accessing high-quality images compared with previous Landsat satellites (Loveland et al. 2008; Lulla et al. 2013; Roy et al. 2014). Several recent efforts such as Verpoorter et al. (2014) and Liao et al. (2014) produce global lake inventories using circa-2000 Landsat images included in the Global Land Survey (GLS) 2000 dataset. These lake mapping products are not validated using rigorous quality assurance and quality control (QA/QC) processes, and may contain both commission and omission errors due to diverse water surface appearance, narrow river segments, unavoidable cloud contamination, mountain 
shadows, etc. In addition, the mapped lake extents reflect the situation at the acquisition dates associated with the source images selected by the GLS project, which is not targeted to lake studies. These acquisition dates may not concur with lake stable seasons across different regions, thus the derived results are subject to large area uncertainties due to lake seasonal variability.

Lakes exhibit long-term changes in surface water extent due to their own life cycles, climate change, and anthropogenic impacts, but many of them also vary greatly from season to season. With the ultimate goal of detecting the long-term trend of lake areal change, we need to map representative lake extents, and assess and suppress the noise of seasonal variations in lake extent. One effective solution is to map lakes during their stable periods when inundation extents are minimally affected by meteorological conditions. The OLI onboard Landsat 8 is collecting a great quantity of images at an unprecedented rate of $\sim 550$ scenes a day (http://landsat.gsfc.nasa.gov/?p=3186). This intensive image acquisition capability allows us to select the representative lake extent derived from multiple images acquired during lake stable seasons and to assess lake seasonal variability.

This study proposes a new mapping and compositing strategy to produce representative circa-2015 lake maps and address seasonal variability issues in lake mapping at continental and global scales, and intends to prototype this strategy in mainland Oceania using Landsat 8. Mainland Oceania provides an ideal but challenging case study for this research, because not only this region is covered by Landsat 8 cloudfree images more intensively than any other continents but also arid lakes in western and central Australia vary a great deal both seasonally and inter-annually. This paper first 
determines lake stable seasons across the study area, and collects all largely cloud-free Landsat 8 images within the seasons. With these images, we delineate lake extents using a highly applicable automated adaptive lake mapping method, and then determine the intermediate size of each lake as its representative extent to generate the composite circa2015 lake map for Oceania. Finally, the benefits of Landsat 8 in multi-temporal lake mapping are discussed.

\section{Materials and Methods}

\subsection{Study Area}

As illustrated in Fig. 1a, the study area for this paper is mainland Oceania, defined here as the continent of Australia and the islands of New Zealand. This region contains a broad variety of climate zones though generally warm with an average temperature above the freezing point (Pink 2012). Australia is large enough to contain tropical rainforests in the north, extensive arid deserts in the center, and temperate regions in the cooler south. Rainfall in Australia is seasonal and the rainy season varies across the continent. A tropical monsoon system in the north brings rainfall in the Austral summer leaving a dry winter. The coasts of Queensland, New South Wales, and Victoria, east of the Great Dividing Range, experience a more maritime climate with regular summer and some winter rainfall due to proximity to the ocean. Southwestern Australia experiences a wet winter season brought by westerly winds and cold fronts followed by a hot, dry summer. Most of the interior of Australia has very low year-round rainfall, with sporadic thunderstorms (Kuleshov et al. 2002). New Zealand, being a group of islands, is generally dominated by a marine climate. Oriented roughly north-south, New Zealand 
does experience a temperature gradient from the more tropical North Island to the more temperate and mountainous South Island. 

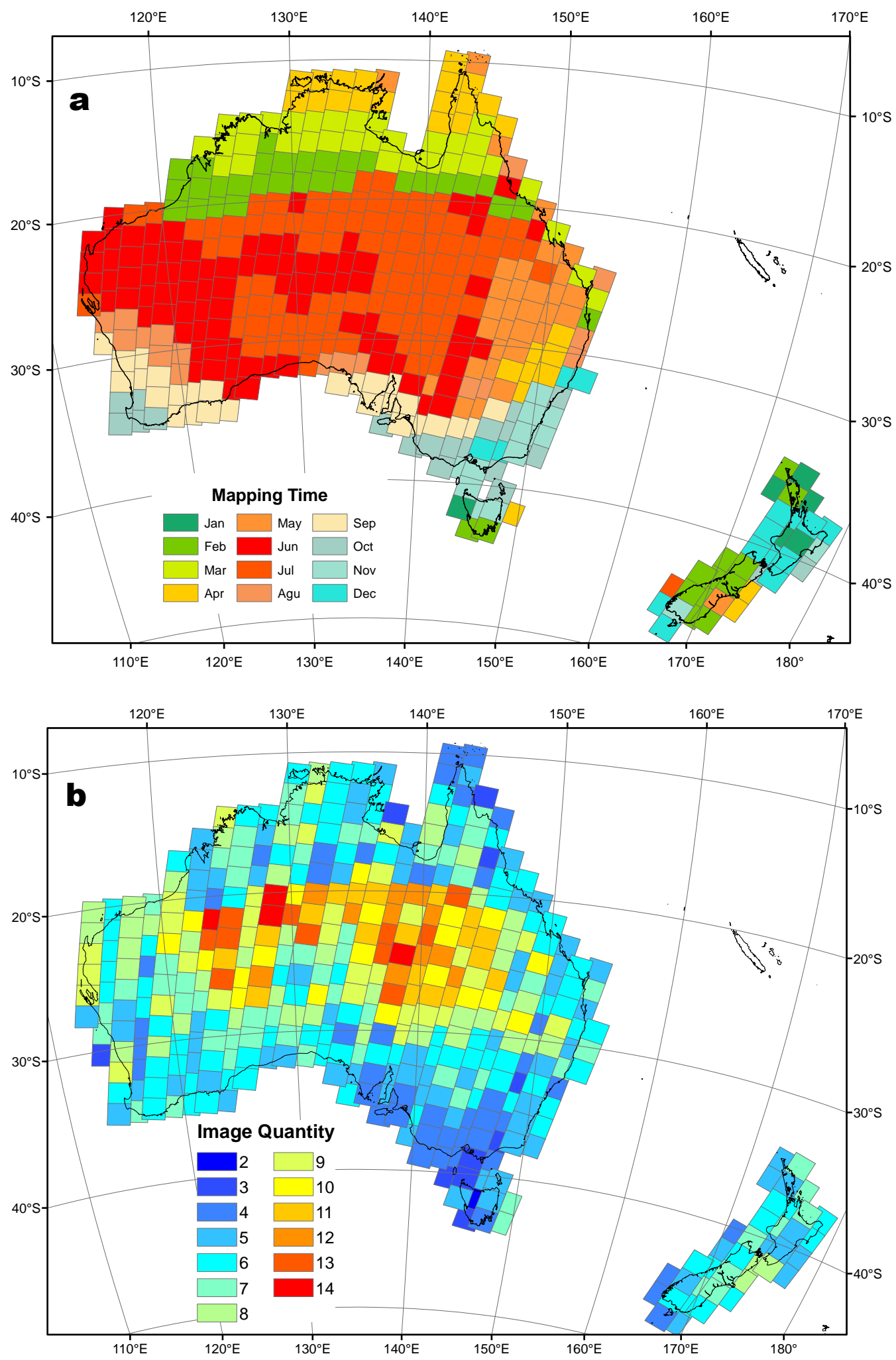
Fig. 1. Study area and data used. (a) Optimal mapping months; (b) Image acquisition map. Each square outlines the footprint of each WRS-2 tile covering the study area.

With the particularly flat landscapes on the Western Plateau and in the Central Lowlands, mainland Australia is home to a large group of the world's closed lakes, which are situated in endorheic basins. Many of these lake systems are quite old, extending to the early Tertiary and the end of the Cretaceous, and have been affected morphologically during recurring glacial-interglacial cycles (Dedeckker 1983). In the modern age, these lakes are highly dynamic, even ephemeral, and are quickly filled by episodic heavy rain events and quickly evaporated by the hot, dry climate. They, including the highly variable Lake Eyre, continue to change in their distribution and inundation area. These lake changes represent a sensitive and integrative indicator of regional climate and water cycle change, and greatly impact the local and regional ecological environment. Together with New Zealand, Australia provides an ideal study site to develop the mapping strategy for Landsat 8 to produce representative maps for highly variable lakes.

\subsection{Optimal lake mapping seasons and Landsat 8 images used}

It is important to inventory lakes and interpret long-term changes during lake stable seasons, the periods when lakes are relatively stable in an annual cycle, to reduce seasonal variability. Due to the variable climate zones across Australia and the transitive climate in New Zealand from the north to the south, the lake stable season varies from place to place in Oceania. For example, the rainy season in northern Australia coincides with the summer monsoon season while other areas dominated by winter cold fronts are in dry seasons. New Zealand has highly complicated hydrology driven by interactions 
between the oceans and mountains. Thus the appropriate lake mapping season must be defined individually for each location based on its typical local climate.

We have developed an algorithm, called LakeTime, to select Landsat scenes based on a season defined using climatic and hydrological variables so that lake measurements can be compared spatially and temporally with minimal seasonal or inter-annual interference (Lyons and Sheng in revision). The lake stable season is defined around the month with minimal lake change after the rainy season, and is determined quantitatively using precipitation, potential evaporation, and temperature data provided as monthly global gridded long-term means $(1950$ - 2010) by the Center for Climatic Research at the University of Delaware at a $0.5^{\circ}$ resolution (Matsuura and Willmott 2009, http://climate.geog.udel.edu/ climate/). Fig. 1a shows the relatively stable lake mapping month for each Landsat WRS-2 (Worldwide Reference System) tile in Oceania as determined by LakeTime. The optimal mapping season in the northern coast is April, moving to February further inland, which is after the summer monsoon visits this area. The broad arid and semi-arid regions in western and central Australia have optimal lake mapping months in June and July when lower temperatures limit evaporation from lakes. The optimal mapping months for the southeast and southwestern coasts of Australia are from September to November, immediately following the winter rainy season there. The mapping months for New Zealand are generally earlier for the North Island, December to January, and later for the South Island, February to April, due to the latitudinal temperature gradient and mountain effects.

The circa-2015 lake map is produced using Landsat 8/OLI images acquired from May 2013 to August 2015. As indicated above, there are two main criteria of selecting 
images: first, to reduce seasonal and inter-annual variability by gathering images whose acquisition dates are concentrated around the optimal lake mapping season, when lakes are relatively stable; second, to only select images with low cloud contamination usually less than $10 \%$ to $30 \%$ the cloud coverage depending on image availability. A total of $\sim 3,300$ Landsat 8 scenes were collected to conduct the continental mapping, about five times more than the Landsat 7 images used in producing the circa-2000 continental lake map. Fig. 1b shows the spatial distribution of the number of selected images for each WRS-2 tile. The counts of available scenes in the arid central Australia (i.e., more than 10) are much higher than along the coasts. Coverage in New Zealand and other islands is largely restricted by cloud contamination. Thus the map displays an inverse pattern to precipitation over Australia, with more cloud-free images in the dry interior. To improve the reliability of multi-temporal lake observations, we ensure that most WRS-2 tiles (> 99.4\% over Oceania) are covered by three or more high-quality images/scenes.

\subsection{Automated adaptive lake mapping}

Theoretically, lakes and other surface water bodies are readily identifiable in each scene owing to their low reflectance in near-infrared (NIR) channels of Landsat sensors (0.8-1.1 $\mu \mathrm{m}$ for MSS (Multi-Spectral Scanner) Band 7, 0.76-0.90 $\mu \mathrm{m}$ for TM (Thematic Mapper) and ETM+ (Enhanced Thematic Mapper Plus) Band 4, and 0.83-0.90 $\mu \mathrm{m}$ for OLI Band 5). However, most lakes in Oceania are salt lakes and are quite diverse in their appearance, even in NIR images. Water turbidity, mineral and chlorophyll content,

presence of aquatic vegetation, snow/ice, and mountain/cloud shadows can all complicate spectral responses of lake water and impose challenges to unambiguous lake mapping. 
The normalized difference water index (NDWI), derived using the green and NIR bands, enhances water features and depresses interfering factors (McFeeters 1996), and has been widely used in water body delineation from satellite images (Lira 2006; Ouma and Tateishi 2007; Xu 2006). NDWI, derived as (Band3 - Band5)/(Band3 + Band5) for OLI and (Band2 - Band4) $/($ Band $2+$ Band4) for TM and ETM+, is less sensitive to mineral content in lake water and demonstrates better capability in delineating water bodies from land than individual bands. Top-of-atmosphere (TOA) reflectance of these bands calculated from Landsat DN (Digital number) values (Chander et al. 2009) are used in NDWI computation. Lake maps can then be produced by segmenting an NDWI image. However, a large number of lakes in the studied Oceania cannot be properly delineated in the image using a single universal threshold due to varying lake conditions.

We have developed an automated, adaptive lake mapping approach implemented through image segmentation at both global and local levels, which simulates a human operator's delineating procedures ( $\mathrm{Li}$ and Sheng 2012; Qiao et al. 2012). In the global level of segmentation, lakes are first located by segmenting the entire NDWI image using a loose initial threshold. The purpose of this global segmentation is to initially detect potential lakes rather than precisely delineate them. Next, each identified lake is treated as an object and further fine-tuned only in the area surrounding the lake (i.e., a buffer zone) by histogram segmentation at the local level. The local-level segmentation is then implemented iteratively to precisely identify the lake extent until the iteration converges to a stable segmentation result. This adaptive method is highly automated and effective in mapping lakes under various complex water conditions, and is insensitive to common classification problems including lake ice, turbidity, and aquatic vegetation. In addition, 
terrain variables such as slope and hillshade, derived from digital elevation data and solar angles synchronous with the image acquisition, are used to differentiate mountain shadows from lakes ( $\mathrm{Li}$ and Sheng 2012). The output of this mapping procedure is a lake layer in the vector geographic information systems (GIS) format for each Landsat image. All the lake layers mapped from Landsat 8 scenes are projected to a customized equal area map projection suitable for Oceania to preserve the area property.

\subsection{Using 2000 reference lake layer in Landsat 8 mapping}

As part of our global mapping project, the circa-2000 lake map has already been generated using Landsat 7/ETM+ imagery and the above-mentioned image selection and mapping methods. Though the adaptive method performs rather well and greatly reduces the subsequent editing efforts, QA/QC procedures are still necessary to achieve the optimal product quality. Following the automated lake extraction is intensive QA/QC procedures to ensure that the extracted lake extents well match the source image. A semi-automated tool (Wang et al. 2014) is developed to fix any identified mapping issues. River segments are also removed in the QA/QC process using both automatically generated shape indices and manual inspection. All lake layers passing the quality control process are composited together using an automated lake mosaicking tool to resolve possible inconsistencies along the overlapping margins between Landsat scenes. As such, the circa-2000 continental lake map of Oceania (Fig. 2) was generated from more than 500 Landsat 7 ETM+ images collected between 1999 and 2003. This map is used as the reference layer for circa-2015 Landsat 8 lake mapping mainly to determine the initial threshold for global-level segmentation. 


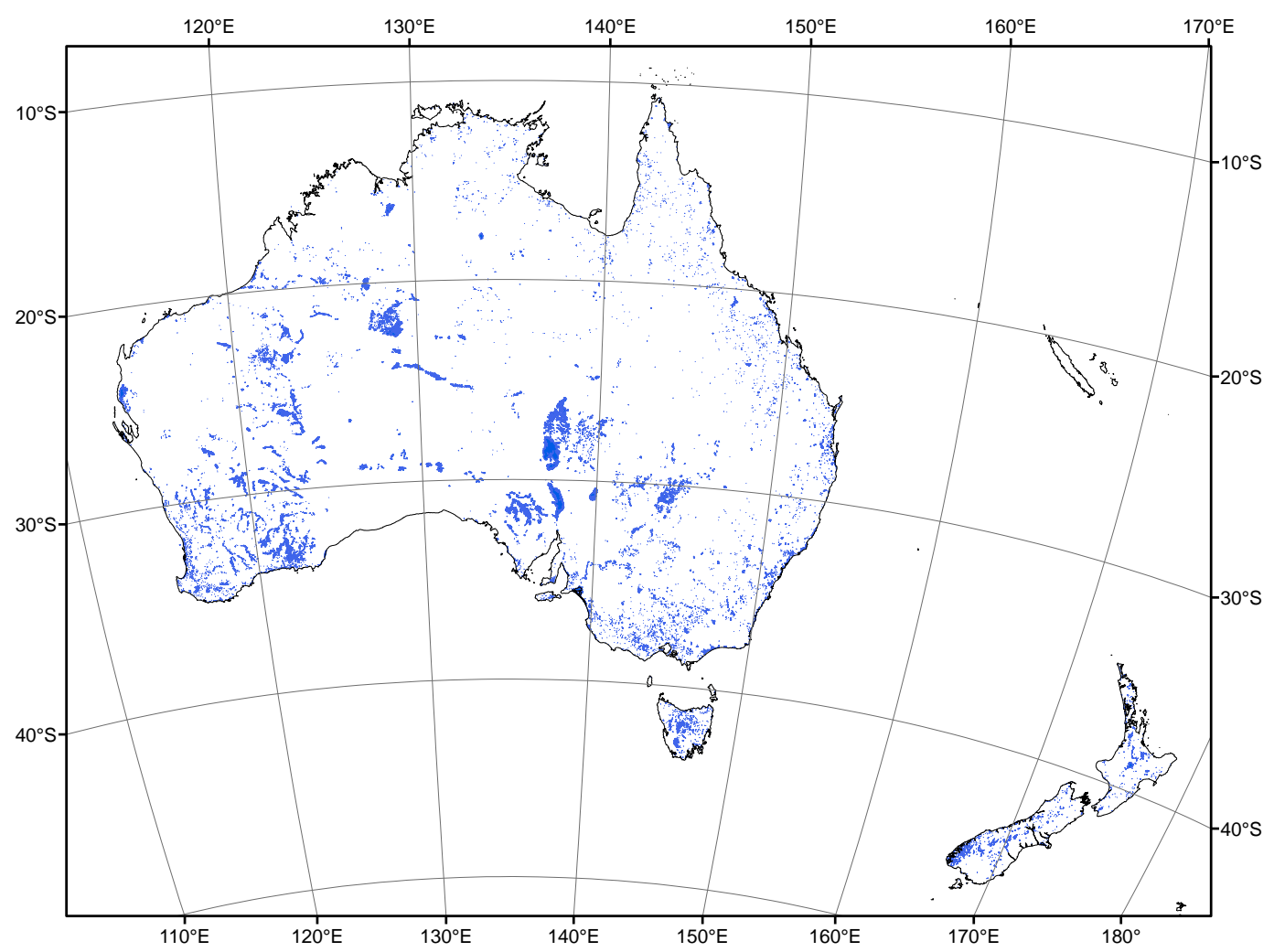

Fig. 2. Circa-2000 reference lake map. The map was produced using similar mapping methods and 500+ Landsat 7/ETM+ images collected between 1999 and 2003.

\subsection{Reducing seasonal variability by selecting representative lake extent from multiple}

\section{Landsat 8 acquisitions}

The adaptive mapping algorithm, as previously described, produces multiple lake layers from OLI images acquired for each WRS-2 tile. Multiple scenes with various acquisition dates usually concur during the optimal mapping period within one tile. As lakes are dynamic and sometimes intermittent, size discrepancy of the same lake is expected on different acquisition dates. While these multiple-date mappings offer a selection pool of lake sizes in the optimal period, they also induce technical challenges in 
lake composition across broader regions. In addition, marginal overlaps exist between adjacent WRS-2 tiles; water bodies across or overriding scene boundaries are mapped incomplete or disconnected. As a consequence, lake features in a direct composite of scene maps are commonly found in complex topological patterns such as merging, nesting, and overtopping. To address these issues, we here develop a robust scheme to compose a complete, single-layer mosaic of scene maps by selecting representative lake extents at the median-sized condition in the optimal period with assistance of the produced circa-2000 reference lake map.

The schematic logic flow of our lake composition is illustrated in Fig. 3. Lake features mapped from all individual scenes (Fig. 3a) are first merged and superimposed to form a raw composite layer (exemplified in Fig. $3 b$ where lakes are merged from four source OLI scenes of two WRS-2 tiles; each scene denoted by one distinct color). In this raw composite, the original lake individuals remain unaltered in location and geometry, but are grouped into numerous clusters based on spatial concurrence. Here a lake cluster is defined as a hypothetical entity representing the maximal inundation extent dissolved by overlapped lake features mapped from multiple scenes, and is topologically independent from any other clusters (Fig. 3c, two clusters $C 1$ and $C 2$ grouped from Fig. $3 b)$. Each cluster is a unique spatial unit where the representative, median-size lake extent could be subsequently identified from overlapped lake features. 


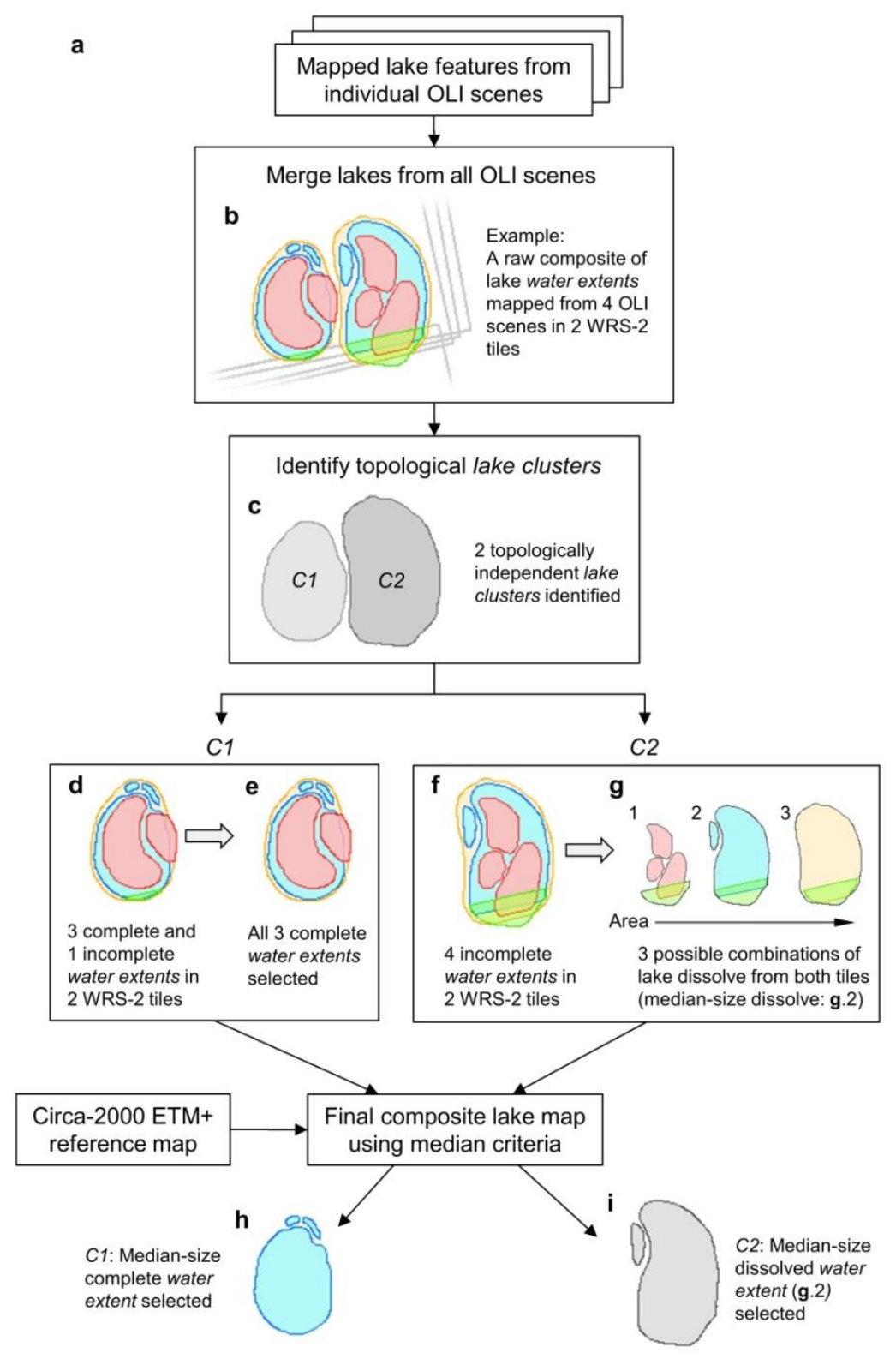

Fig. 3. Schematic illustration of the logic flow of lake composition from multiple OLI scenes.

We use the examples of $C 1$ and $C 2$ to further illustrate two typical situations where the existence of incomplete water extents complicates the lake composition procedure. Here a water extent refers to the total lake extent in a cluster, usually an aggregation of multiple individual lake features, mapped from the same scene or 
acquisition date (e.g., in Figs. 3d and 3f, each water extent denoted by a unique color). A water extent is considered to be complete if it does not touch the scene boundary. In cluster $C l$, one incomplete water extent (the green feature in Fig. 3d) concurs with three complete extents, and is considered as an invalid lake extent and excluded in the selection process (Fig. 3e). In case of a lake overrides adjacent scenes, none of the images can map out the lake completely alone. As illustrated in cluster $C 2$, all four water extents mapped from the two WRS-2 tiles are incomplete (Fig. 3f); under this circumstance, different combinations of incomplete water extents are dissolved across tiles to form a series of more complete lake entities (Fig. $3 \mathrm{~g}$ with 3 possible dissolve combinations). In either cluster, the median-size water extent was then used as the output in the final composite lake map (Fig. 3h for $C 1$ and Fig. 3i for $C 2$ ).

In addition, the historical lake extents documented in our circa-2000 map is also utilized as a reference in the circa-2015 lake composition. As lakes are temporarily dynamic, we here do not intend to use any historical lake size, but refer to the historical lake existence to suggest a high likelihood of lake existence at present. Two possible scenarios are considered. In the first scenario where a present cluster overlaps lake features in the circa-2000 reference, we assume that the present lake existence in this cluster is confirmed; in this case, the mapped median-size water extent is used in the final composite (illustrated in Fig. 3). In the second scenario where a cluster overlaps no historical lakes, the median selection also accounts for the frequency of OLI scenes without lakes mapped out in this cluster; for instance, no lake feature is output in the final composite if a cluster has a highly intermittent water extent that appears on less than half of the image acquisition dates. Using this above-mentioned procedure in each identified 
cluster, we are able to construct a complete circa-2015 lake composite that reflects representative surface conditions during lake stable seasons across the studied Oceania.

\section{Results}

The developed lake mapping procedures are used to process all the $\sim 3,300$ OLI scenes and produce a vector lake layer for each image. The mapping accuracy in general is high even though salt lakes and dry playas in Oceania are challenging. Typical of desert lakes, Lake Disappointment is an ephemeral salt lake in Western Australia at $\left(122.8^{\circ} \mathrm{E}, 23.5^{\circ} \mathrm{S}\right)$, and is fully covered by Landsat 8 in the WRS-2 tile P109R076 (i.e., Path 109 and Row 076). A total of ten images were acquired around July (the determined optimal mapping month for this tile) from the first $2+$ year's Landsat 8 operation. Surrounded by sand dunes, this lake also exhibits various surface conditions seen in the image acquired on July 29, 2013 (Fig. 4a), and provides a challenging case to examine the automated mapping results. The full lake is properly delineated (as outlined in red) using an automatically determined NDWI threshold of -0.22 . In the image of June 11 , 2013 (Fig. 4b), the western portion of the lake is covered by scattered clouds. Cloud contamination imposes another challenge to the optical remote sensing of surface water. However, our adaptive mapping algorithm is shown to be less sensitive to interfering factors, including this minor cloud contamination, and decently delineates this lake extent using an NDWI threshold of -0.23 . The lake extents identified from all ten images are rather consistent with areas ranging from $1041.46 \mathrm{~km}^{2}$ to $1109.15 \mathrm{~km}^{2}$, indicating a high precision of our algorithm in multi-temporal lake mapping. 

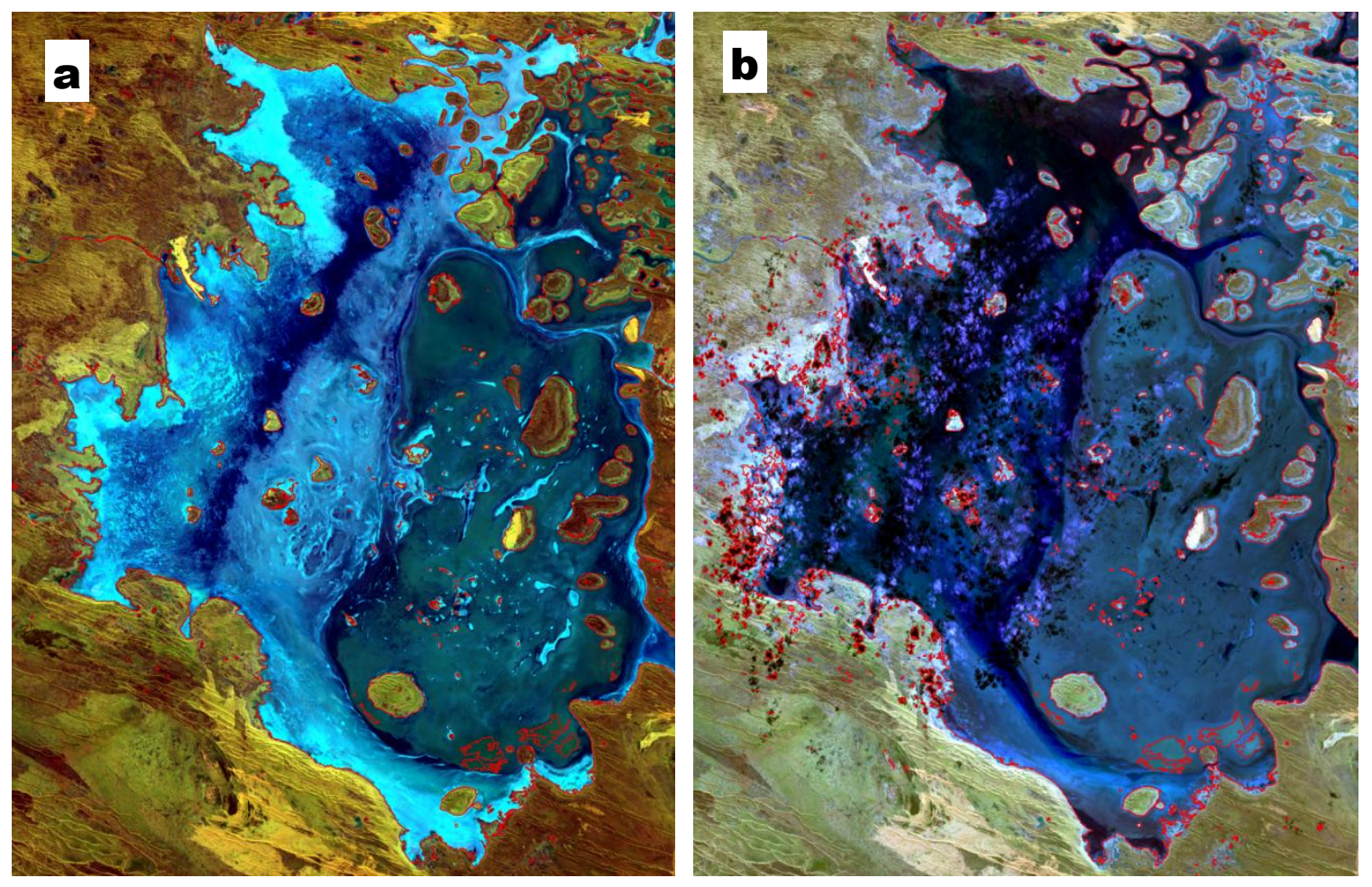

Fig. 4. Adaptive lake mapping results for Lake Disappointment. (a) Lakes delineated from July 29, 2013 image; (b) Lakes mapped from June 11, 2013 image. There are cloud covers over that main lake and cloud shadows on land along the southwestern shore.

Covered by a large number of OLI images, Lake Disappointment also provides a good example for examining the performance of the developed lake compositing scheme. In addition to complete spatial coverage by ten images of tile P109R076, Lake Disappointment is also partially covered by P110R076 (Fig. 5a) and P109R077 (Fig. 5b) with eight and ten images, respectively. As explained in Section 2.5, when complete lake extents are available for a lake cluster, its incomplete extents do not participate in the selection process. The final selection for Lake Disappointment is based on all the complete extents mapped from P109R076 on ten different acquisition dates (Fig. 5c). Of the ten lake areas (i.e., $1058.98 \mathrm{~km}^{2}$ on $2013 / 06 / 11,1061.09 \mathrm{~km}^{2}$ on $2013 / 07 / 13,1076.84$ $\mathrm{km}^{2}$ on $2013 / 07 / 29,1094.91 \mathrm{~km}^{2}$ on $2013 / 08 / 14,1109.15 \mathrm{~km}^{2}$ on $2013 / 08 / 30,1094.70$ 
$\mathrm{km}^{2}$ on $2014 / 06 / 14,1084.17 \mathrm{~km}^{2}$ on $2014 / 06 / 30,1041.46 \mathrm{~km}^{2}$ on $2014 / 08 / 01,1057.10$ $\mathrm{km}^{2}$ on $2015 / 07 / 19$, and $1075.80 \mathrm{~km}^{2}$ on $\left.2015 / 08 / 04\right)$, the median lake extent (1076.84 $\mathrm{km}^{2}$ ) is selected. This water extent was mapped on 2013/07/29, which is in the same month identified as the optimal mapping season.
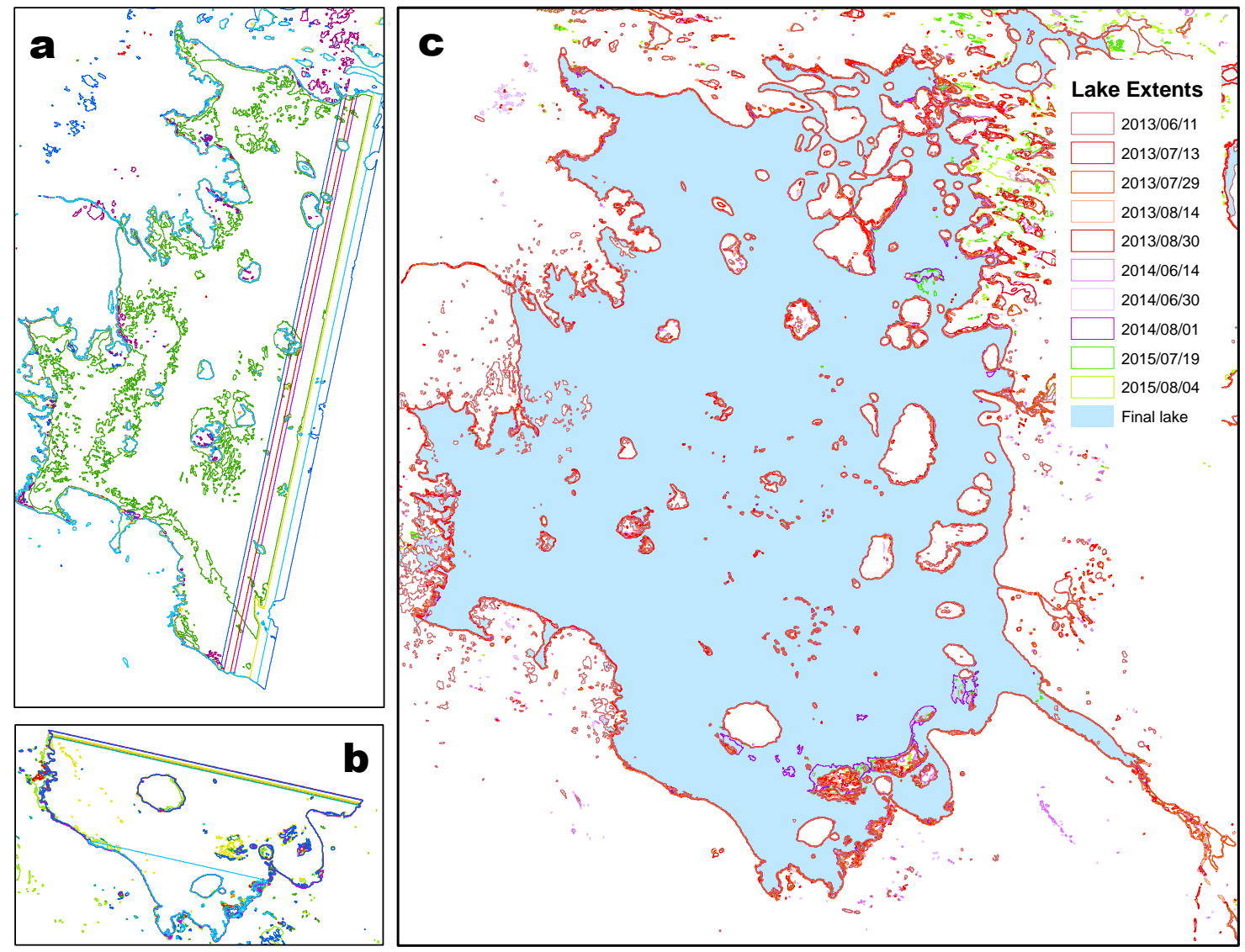

Fig. 5. Final lake produced from the compositing scheme. (a) Partial lake extents mapped from P110R076 tile; (b) Partial extents from P109R077 tile; and (c) Complete lake extents from ten images of P109R076 tile.

The proposed lake compositing scheme also demonstrates to be robust to cloud contaminations. In general, clouds cover about $60 \%$ of the land surface at any given time (Rossow and Schiffer, 1999). Despite the overall high quality of our collected images, 
minor cloud contamination inevitably exists in local areas. In our compositing scheme, cloud-contaminated lake extents are usually filtered out as they tend to underestimate the lake area, thus lowering their likelihoods of being selected as the median. This can be demonstrated in the case of Lake Disappointment. The lake extent mapped from the 2013/06/11 image (Fig. 4b) with an area of $1050.98 \mathrm{~km}^{2}$ is relatively small compared to lake extents extracted from other images due to the partial cloud cover, and is therefore not selected for inclusion in the final lake composite. The compositing method is also capable of handling cloud shadows, which also interfere with lake mapping. In the same image (Fig. 4b) cloud-cast shadows on land are misrecognized as water bodies on the southwestern side of the lake, but these false water bodies are not shown in other cloudfree images. Our compositing scheme takes both the cloud-contaminated and cloud-free cases into the process of median condition selection, and thus these false lakes are excluded in the final lake map.

As the primary output of the multi-temporal lake mapping and compositing procedures, the circa-2015 continental lake map of Oceania is shown in Fig. 6a. The distribution of lakes follows the general pattern of topography and lake types. Large salt lakes are located in the western and central Australian endorheic lake basins while small fresh water lakes are distributed along the coasts. Fig. $6 \mathrm{~b}$ illustrates a map of the NDWI thresholds that the adaptive mapping algorithm determines for each lake. NDWI theoretically falls within the range of -1 and 1 , with water pixel values generally greater than 0 and land pixel values less than 0 . Thus, a threshold around 0 is usually adequate to separate water bodies from land. However, the NDWI thresholds for segmenting water bodies in natural world are generally far more complicated than theoretically expected. 
NDWI of salt lakes may reach as low as -0.6 whereas some land features such as bare soils may have positive values high enough to be confused as water bodies. Oceania is such an area with wild NDWI values, and provides a challenge to the NDWI-based mapping methods. It is interesting to analyze NDWI threshold values at regional scale as illustrated in Fig. 6b. These lake-specific threshold values vary greatly from -0.60 to 0.78 , implying that a single universal threshold would not segment lakes adequately. The spatial distribution of these thresholds also depends on lake types. Among water pixels, low values (i.e., $<-0.2)$ are mainly found in salt lakes across the extensive endorheic basins, making lake delineation challenging. Furthermore, the NDWI values of surrounding dry sands are not as low as vegetated regions. A carefully selected threshold (normally lower than -0.2) is needed to separate them. Positive thresholds appear mainly in the regions along the coast, where freshwater NDWI values are relatively high and the surrounding vegetation values are particularly low. 

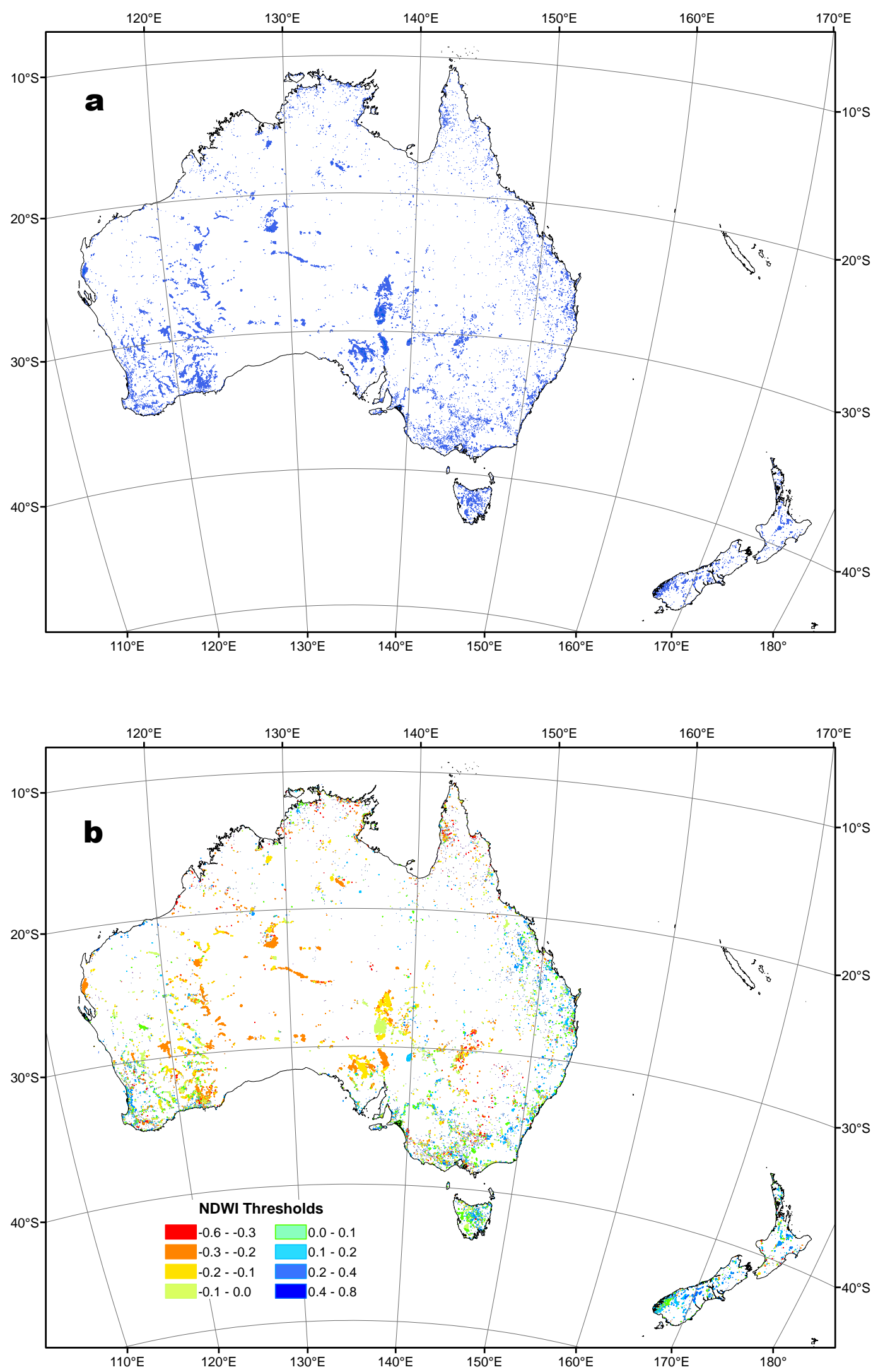
Fig. 6. (a) Produced circa-2015 lake map; and (b) Automatically derived individual thresholds used in final lake segmentation.

Although the circa-2000 lake data set was used as a reference layer in the circa2015 lake mapping to set initial NDWI thresholds in lake mapping and to guide the median selection in multi-temporal compositing, the final local-level NDWI segmentation for lake boundary delineation and the final median lake extent selection are completely based on Landsat 8 images. Thus, the two data sets can be considered independent. The two-phase lake mapping results are rather comparable, both in lake count and inundation area. Over the mainland Oceania, the numbers (total areas) of lakes larger than $0.01 \mathrm{~km}^{2}$ are $41,484\left(462,531.7 \mathrm{~km}^{2}\right)$ and 47,046 $\left(460,881.7 \mathrm{~km}^{2}\right)$ in circa2000 and circa-2015, respectively. The differences mainly reflect the lake changes over the 15 years. However, Landsat 8 tends to capture more small lakes likely due to its better detection capability attributed to the improved radiometric resolution and the high signal-to-noise ratio (SNR).

The Lake Eyre basin $\left(\sim 1.14\right.$ million $\left.\mathrm{km}^{2}\right)$ in central Australia is one of the world's largest endorheic basins, and contains a group of salt lakes exhibiting extremely high seasonal and inter-annual variability. We here briefly compare the circa-2015 lake product (Fig. 7a) in the basin with various other lake data sets, including Global Lakes and Wetlands Database (GLWD, Fig. 7b), MODIS water mask product (MODIS WM, Fig. 7c), Shuttle Radar Topography Mission (SRTM) Water Body Data (SWBD, Fig. 7d), and GlobCover 2009-Product's water bodies (GlobCover, Fig. 7e). These maps reveal large inconsistencies in both the abundance and extents of water bodies in the basin among different data sources. GLWD (Lehner and Döll 2004), a compiling effort from 
existing data sources from the early 2000 s, completely omits the main water bodies of Lake Eyre. The MODIS WM map (Carroll et al. 2009) misses small and large water bodies and the mapped water extents are small compared with our results. On the contrary, the SWBD (Farr et al. 2007) and GlobCover maps (Bontemps et al. 2011) show larger lake extents than our results. According to the statistics of net lake area among different data sets, our circa-2015 lake inventory shows an intermediate result (10,408.5 $\left.\mathrm{km}^{2}\right)$, falling between the larger lake extents from GlobCover $\left(19,389.9 \mathrm{~km}^{2}\right)$ and SWBD $\left(14,334.1 \mathrm{~km}^{2}\right)$ and the smaller ones from MODIS WM (3,247.1 km²) and GLWD (394.6 $\mathrm{km}^{2}$ ). In addition, our lake map contains small-size lakes (less than $0.1 \mathrm{~km}^{2}$ ) which cannot be identified in the other four lake datasets due to their use of coarser-resolution data sources.

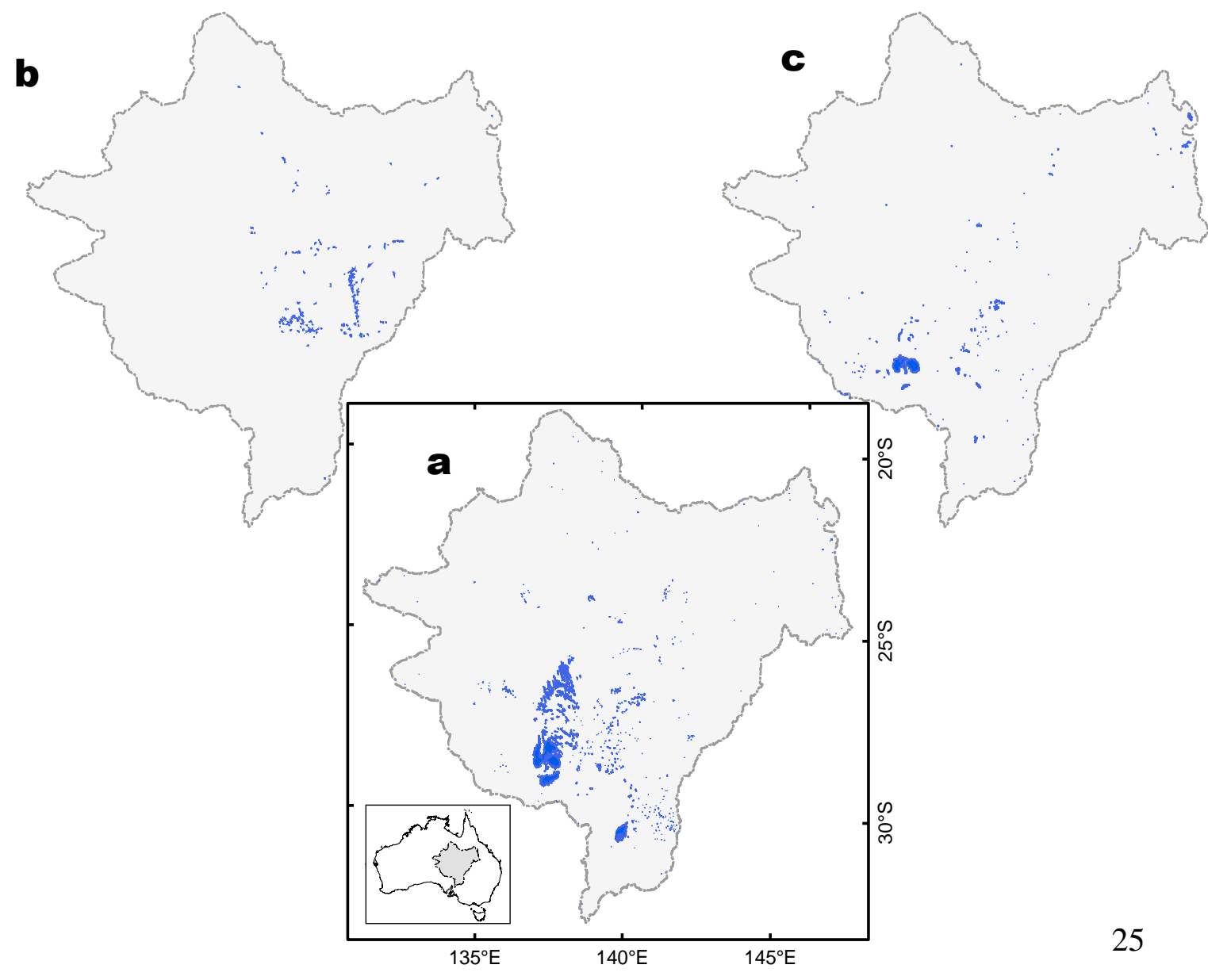



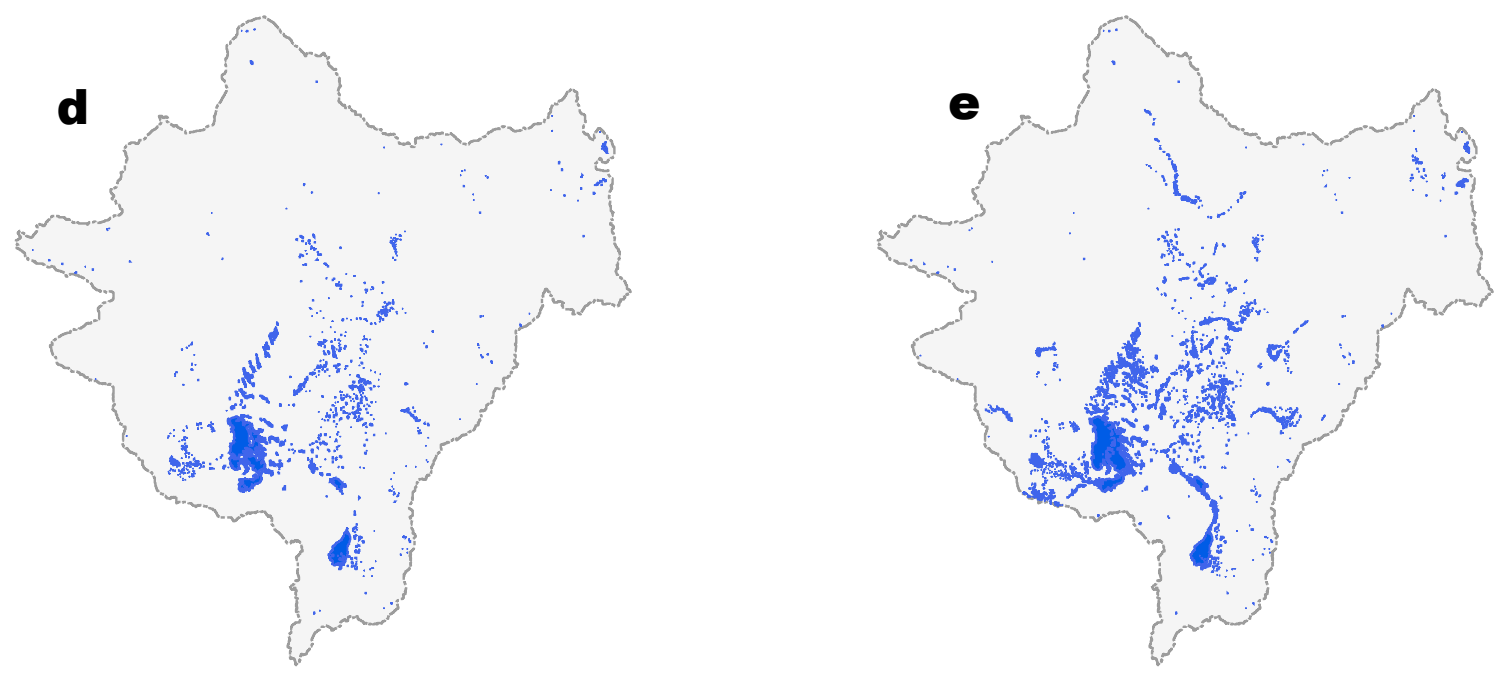

Fig. 7. Lake product comparison in Lake Eyre basin. (a) New circa-2015 lake product; (b) Global Lake and Wetland Database (GLWD); (c) MODIS water mask; (d) Shuttle Radar Topography Mission (SRTM) Water Body Data (SWBD); and (e) GlobCover Product.

The intermediate lake results are achieved from the compositing scheme by selecting the median lake extent from multiple observations. The number of lake extents for each lake cluster is crucial to characterizing lake size variability and to the reliability of lake mapping. Fig. 8a shows the number of times each lake has been mapped out. The majority of lakes in the final composite were selected from 4-15 lake extents. Lakes in the overlapping areas between WRS-2 tiles are captured even more frequently, up to 46 times. In general, lakes in central Australia, often under clear sky, are mapped more intensively than coastal regions. 

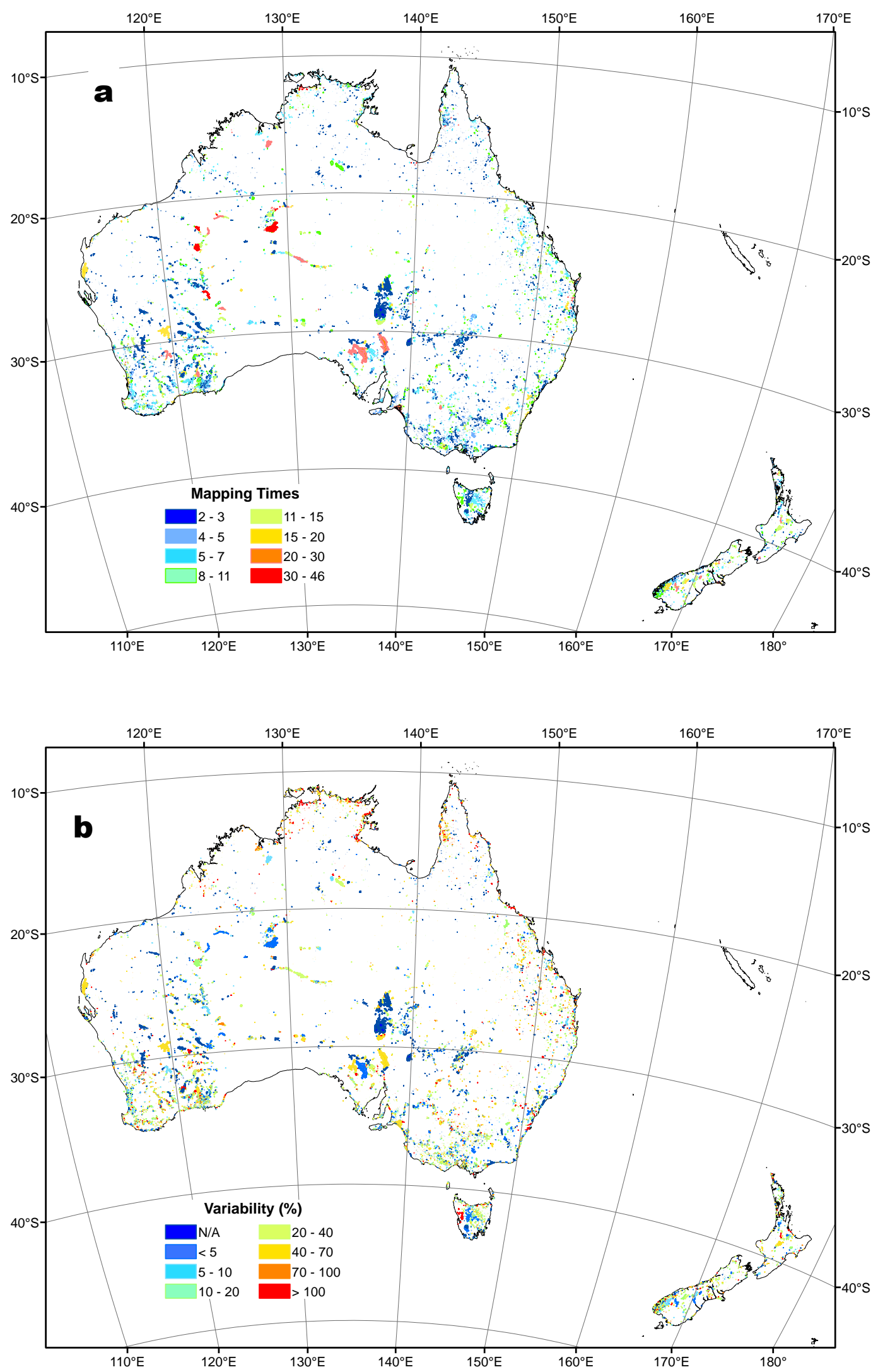
Fig. 8. (a) Lake specific mapping times map; and (b) Size variability among overlapped lake extents.

The variability of lake extents for each lake included in the composite describes how much the lake varies seasonally and inter-annually during the image acquisition season, and is defined as the ratio (in percentage) of the standard deviation among the mapped lake extents to the selected lake size. Fig. 8b shows the lake-specific size variability. Endorheic lakes in Central Oceania in general do not show significantly higher variability than those in coastal areas, indicating the effectiveness of using images acquired during lake-stable seasons in reducing seasonal variability. Some high variability of small lakes is found in coastal areas as they are more sensitive to size changes. The variability metrics is also informative to the subsequent QA/QC procedures since high variability may also flag lakes with high potential mapping error.

Due to the variable nature of lake water conditions and also the surrounding environment, a certain level of manual inspection is unavoidable in any broad-scale lake mapping effort. Therefore, the final process after the aforementioned automated lake mapping and compositing is the QA/QC procedures to validate that the extracted lake polygons appear correct as compared with the source Landsat images. Even though the automatically generated lake layer is of a high quality, still, tens of hundreds of lakes require manual editing in a GIS. The circa-2000 map was produced from more than 500 images, and it took an operator about two months to go through the QA/QC procedures. Circa-2015 is generated from 3,300 multi-temporal images, yet the QA/QC workload is less intensive (about two weeks), which further testifies to the reliability and effectiveness of our mapping and compositing methods. Not only can these methods 
reduce substantive mapping errors such as those induced by cloud contamination, but also the seasonal and inter-annual variability. In addition, the variability metrics quantified by the compositing procedure also provides an informative reference for the operator to better identify problematic lakes during the QA/QC procedures.

\section{Discussion on Landsat 8's benefits in lake mapping}

The experiment of regional-scale representative lake mapping in Oceania using Landsat 8 has been successful, and the success is attributed to the improvement of its sensor and the enhanced image acquisition plan. We should point out that Landsat 8 has advantages in lake mapping over its ancestors. First of all, the 12-bit radiometric resolution and the improved sensitivity of Landsat 8's OLI sensor result in higher SNRs, essential to water body identification. Water bodies are dark objects with a reflectance usually lower than $10 \%$ in optical bands, and their mapping benefits greatly from these improvements. NDWI image segmentation is an effective water body mapping method, and histogram segmentation algorithms are widely used. Though NDWI enhances the difference between water bodies and land background, it is more sensitive to noise than the original green and NIR bands. Compared to Landsat 7 ETM+ (an 8-bit instrument), Landsat 8 OLI greatly improves its SNRs in the green and the NIR bands, from 37 to 304 and 34 to 201, respectively (Morfitt et al. 2015). As a result, Landsat 7 NDWI images are much noisier than Landsat 8 ones. The bumpy NDWI histogram curve of a noisy NWDI image makes the segmentation difficult and may lead to erroneous water identification. Fig. 9 compares the histograms of Landsat 7 and Landsat 8 NDWI images in the vicinity of Lake Disappointment, acquired on May 30, 2000 and June 01, 2015 
respectively. While the Landsat 7 histogram (red) is rough with high-frequency spikes, the Landsat 8 histogram (blue) in two distinct modes is much smoother, allowing more precise segmentation threshold determination and reliable lake mapping Though we do not have a quantitative measure on the improvement in precision and reliability for all the thousands of lakes mapped, it is common for Landsat 8 to show smoother NDWI curves in all the inspected cases.

In addition, the improved geometric fidelity of Landsat 8 guarantees the precise geo-referencing required in multi-temporal lake mapping. We did not encounter any misregistration issues in processing these $\sim 3,300$ Landsat 8 images in Oceania, whereas a few Landsat 7 images out of more than 500 were found offset when we used them in mapping circa-2000 lake extents. More importantly, the increased daily acquisition rate of Landsat 8 images is essential to the success of continental-scale representative lake map production using multi-temporal images. The developed lake extent compositing algorithm takes advantage of the large number of observations to reduce cloud contamination, remove inadequately mapped lake extents, improve the mapping results greatly, and reduce the subsequent $\mathrm{QA} / \mathrm{QC}$ efforts significantly. The previous Landsat missions acquired images at a lower rate, and might not capture enough quality images during lake stable seasons. Many regional-lake mapping efforts, including our circa-2000 lake mapping, selected only one quality image per WRS-2 tile to map lakes. However, the produced lake maps are less representative and can not produce an assessment of seasonal variability of the mapped lake size. 


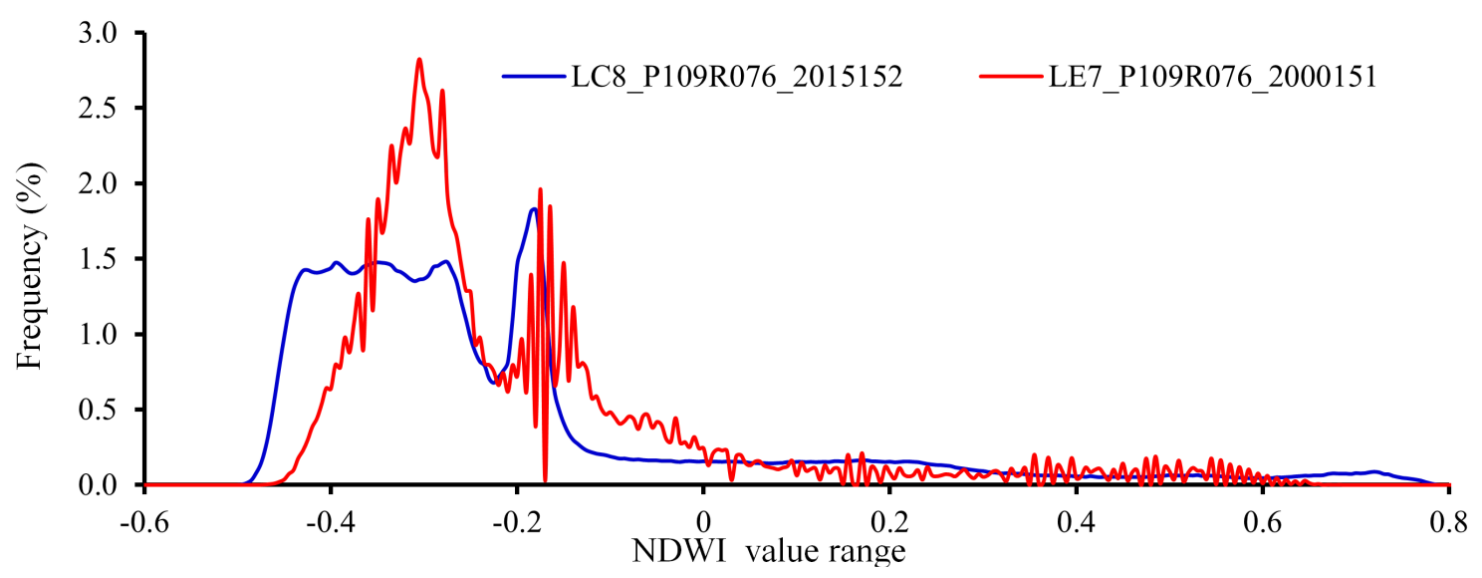

Fig. 9. Histogram comparison of Landsat 7 and Landsat 8 images in the vicinity of Lake Disappointment. The Landsat 8 NDWI histogram (blue) is much smoother than the Landsat 7 one (red).

\section{Conclusions}

This paper presents a set of approaches in image selection, water body identification, and lake extent compositing, suitable for representative lake mapping at continental and global scales. The strategy of acquiring images during lake stable seasons is the first step to produce representative lake maps at continental scales with minimal seasonal variations. The adaptive mapping algorithms are robust and reliable for delineating lake boundaries using automatically determined, lake-specific NDWI thresholds. With the adequately mapped lake extents, the compositing scheme produces final continental lake maps using median selection in the vector domain. The method can not only reduce the impacts of seasonality and inter-annual variability and produce a variability assessment, but also mitigate cloud contamination effects, and significantly reduce labor costs in the subsequent $\mathrm{QA} / \mathrm{QC}$ process. As such, the final lake maps at 
continental scales are reliable and representative of the mapping episode (i.e., circa2015).

The proposed strategy and methods have been successfully used in Oceania, mapping both salt and freshwater lakes across this challenging continent. The improved signal-to-noise ratio and radiometric resolution as well as the increased daily acquisition rate of Landsat 8 images are essential to the success of continental-scale representative lake extent mapping. As the Landsat 8 mission continues acquiring high-quality images, these methods are ready to be applied to other continents.

\section{Acknowledgments}

This work was supported in part by the U.S. Geological Survey (USGS) Landsat Science Team Program Grant G12PC00071.

\section{References}

Alsdorf, D.E., Rodriguez, E., \& Lettenmaier, D.P. (2007). Measuring surface water from space. Reviews of Geophysics, 45, 24

Benson, B.J., \& MacKenzie, M.D. (1995). Effects of sensor spatial resolution on landscape structure parameters. Landscape Ecology, 10, 113-120

Bontemps, S., Defourny, P., Bogaert, E.V., Arino, O., Kalogirou, V., \& Perez, J.R. (2011). GLOBCOVER 2009-Products description and validation report

Bryant, R.G. (1999). Application of AVHRR to monitoring a climatically sensitive playa. Case study: Chott el Djerid, southern Tunisia. Earth Surface Processes and Landforms, 24, 283-302 
Carpenter, S.R., Fisher, S.G., Grimm, N.B., \& Kitchell, J.F. (1992). Global Change and Fresh-Water Ecosystems. Annual Review of Ecology and Systematics, 23, 119-139

Carroll, M., Townshend, J.R., DiMiceli, C.M., Noojipady, P., \& Sohlberg, R. (2009). A new global raster water mask at $250 \mathrm{~m}$ resolution. International Journal of Digital Earth, 2, 291-308

Chander, G., Markham, B.L., \& Helder, D.L. (2009). Summary of current radiometric calibration coefficients for Landsat MSS, TM, ETM+, and EO-1 ALI sensors. Remote Sensing of Environment, 113, 893-903

Dedeckker, P. (1983). Australian salt lakes - their history, chemistry, and biota - a review. Hydrobiologia, 105, 231-244

Farr, T.G., Rosen, P.A., Caro, E., Crippen, R., Duren, R., Hensley, S., Kobrick, M., Paller, M., Rodriguez, E., \& Roth, L. (2007). The shuttle radar topography mission. Reviews of Geophysics, 45

Khorram, S. (Ed.) (1999). Accuracy Assessment of Remote Sensing-Derived Change Detection. Bethesda, MD: American Society for Photogrametry and Remote Sensing

Kuleshov, Y., de Hoedt, G., Wright, W., \& Brewster, A. (2002). Thunderstorm distribution and frequency in Australia. Australian Meteorological Magazine, 51, 145154

Lehner, B., \& Döll, P. (2004). Development and validation of a global database of lakes, reservoirs and wetlands. Journal of Hydrology, 296, 1-22

Li, J., \& Sheng, Y. (2012). An automated scheme for glacial lake dynamics mapping using Landsat imagery and digital elevation models: A case study in the Himalayas. International Journal of Remote Sensing, 33, 5194-5213

Liao, A., Chen, L., Chen, J., He, C., Cao, X., Chen, J., Peng, S., Sun, F., \& Gong, P. (2014). High-resolution remote sensing mapping of global land water. Science China Earth Sciences, 57, 2305-2316

Lira, J. (2006). Segmentation and morphology of open water bodies from multispectral images. International Journal of Remote Sensing, 27, 4015-4038

Loveland, T.R., Cochrane, M.A., \& Henebry, G.M. (2008). Landsat still contributing to environmental research. Trends in ecology \& evolution, 23, 182-183

Lulla, K., Duane Nellis, M., \& Rundquist, B. (2013). The Landsat 8 is ready for geospatial science and technology researchers and practitioners. Geocarto International, 28, 191-191

Lyons, E.A., \& Sheng, Y. (in revision). LakeTime: Automated Seasonal Landsat Scene Selection for Monitoring Global Terrestrial Hydrology. Remote Sensing of Environment

McCullough, I.M., Loftin, C.S., \& Sader, S.A. (2012). High-frequency remote monitoring of large lakes with MODIS $500 \mathrm{~m}$ imagery. Remote Sensing of Environment, $124,234-241$ 
McFeeters, S.K. (1996). The use of the Normalized Difference Water Index (NDWI) in the delineation of open water features. International Journal of Remote Sensing, 17, $1425-1432$

Morfitt, R., Barsi, J., Levy, R., Markham, B., Micijevic, E., Ong, L., Scaramuzza, P., \& Vanderwerff, K. (2015). Landsat-8 Operational Land Imager (OLI) Radiometric Performance On-Orbit. Remote Sensing, 7, 2208-2237

Ouma, Y.O., \& Tateishi, R. (2007). Lake water body mapping with multiresolution based image analysis from medium-resolution satellite imagery. International Journal of Environmental Studies, 64, 357-379

Palmer, S.C., Kutser, T., \& Hunter, P.D. (2015). Remote sensing of inland waters: Challenges, progress and future directions. Remote Sensing of Environment, 157, 1-8

Pietroniro, A., Toyra, J., Leconte, R., \& Kite, G. (2005). Remote Sensing of Surface Water and Soil Moisture. In C. Douguay, \& A. Pietroniro (Eds.), Remote Sensing in Northern Hydrology (pp. 119-142). Washington, DC: American Geophysical Union

Pink, B. (2012). 2012 Year Book Australia. In (p. 884). Canberra: Australian Bureau of Statistics

Qiao, C., Luo, J., Sheng, Y., Shen, Z., Zhu, Z., \& Ming, D. (2012). An adaptive water extraction method from remote sensing image based on NDWI. Journal of the Indian Society of Remote Sensing, 40, 421-433

Roy, D.P., Wulder, M., Loveland, T., Woodcock, C., Allen, R., Anderson, M., Helder, D., Irons, J., Johnson, D., \& Kennedy, R. (2014). Landsat-8: Science and product vision for terrestrial global change research. Remote Sensing of Environment, 145, 154-172

Shi, W., Wang, M., \& Guo, W. (2014). Long - term hydrological changes of the Aral Sea observed by satellites. Journal of Geophysical Research: Oceans, 119, 3313-3326

Smith, L.C., Sheng, Y., MacDonald, G.M., \& Hinzman, L.D. (2005). Disappearing Arctic lakes. Science, 308, 1429-1429

Song, C., Huang, B., \& Ke, L. (2013). Modeling and analysis of lake water storage changes on the Tibetan Plateau using multi-mission satellite data. Remote Sensing of Environment, 135, 25-35

Verpoorter, C., Kutser, T., Seekell, D.A., \& Tranvik, L.J. (2014). A global inventory of lakes based on high - resolution satellite imagery. Geophysical Research Letters, 41, 6396-6402

Vorosmarty, C.J. (2002). Global water assessment and potential contributions from Earth Systems Science. Aquatic Sciences, 64, 328-351

Wang, J., Sheng, Y., \& Tong, T.S.D. (2014). Monitoring decadal lake dynamics across the Yangtze Basin downstream of Three Gorges Dam. Remote Sensing of Environment, $152,251-269$

Xu, H.Q. (2006). Modification of normalised difference water index (NDWI) to enhance open water features in remotely sensed imagery. International Journal of Remote Sensing, 27, 3025-3033 


\section{Captions}

Fig. 1. Study area and data used. (a) Optimal mapping months; (b) Image acquisition map. Each square represents the real footprint of each WRS-2 tile covering the study area.

Fig. 2. Circa-2000 reference lake map. The map was produced using similar mapping methods and 500+ Landsat 7/ETM+ images collected between 1999 and 2003.

Fig. 3. Schematic illustration of the logic flow of lake composition from multiple OLI scenes.

Fig. 4. Adaptive lake mapping results for Lake Disappointment. (a) Lakes delineated from July 29, 2013 image; (b) Lakes mapped from June 11, 2013 image. There are cloud covers over that main lake and cloud shadows on land along the southwestern shore.

Fig. 5. Final lake produced from the compositing scheme. (a) Partial lake extents mapped from P110R076 tile; (b) Partial extents from P109R077 tile; and (c) Complete lake extents from ten images of P109R076 tile.

Fig. 6. (a) Produced circa-2015 lake map; and (b) Automatically derived individual thresholds used in final lake segmentation.

Fig. 7. Lake product comparison in Lake Eyre basin. (a) New circa-2015 lake product; (b) Global Lake and Wetland Database (GLWD); (c) MODIS water mask; (d) Shuttle 
Radar Topography Mission (SRTM) Water Body Data (SWBD); and (e) GlobCover Product.

Fig. 8. (a) Lake specific mapping times map; and (b) Size variability among overlapped lake extents.

Fig. 9. Histogram comparison of Landsat 7 and Landsat 8 images in the vicinity of Lake Disappointment. The Landsat 8 NDWI histogram (blue) is much smoother than the Landsat 7 one (red). 